\title{
Resenha de Refúgio, Migração e Cidadania
}

\author{
Review of Refuge, migration and citizenship
}

Larissa Mereccia

Milesi, Rosita; coury, Paula (Org.). Caderno de debates Refúgio, Migrações e Cidadania.

Brasília: Instituto Migrações e Direitos Humanos, v. 13, n. 13, 2018, 124 p.

Refúgio, Migração e Cidadania é um Caderno de debates que abarca uma seleção de artigos acadêmicos que se propõem a discutir o tema da migração pelo viés da sociologia, ainda que em diálogo com outras áreas das humanidades, como o direito e a geografia. Sob edição responsável do Instituto Migrações e Direitos Humanos, que está ligada também ao Alto Comissariado das Nações Unidas para Refugiados, esta obra busca trazer reflexões críticas mais humanizadas sobre um assunto que provoca considerável polêmica em determinados ambientes onde é discutido, principalmente na academia.

Por mais que seja reconhecido que o ato de migrar é intrínseco à história da humanidade, sendo impossível, portanto, dissociar tal processo social do ser humano, a imigração é retratada como um problema da contemporaneidade. Nesse sentido, a mobilidade do indivíduo, impulsionada por uma série de variáveis - do meio ambiente aos conflitos políticos -, encontra-se limitada por uma nova ótica que vem reconfigurando a maneira pela qual os países recebem seus imigrantes. Levando em consideração a pauta do conservadorismo, principalmente no caso brasileiro, é fundamental repensar o tratamento direcionado a esses sujeitos que, por sua vez, mobilizam cada vez mais categorias como "refugiados" ou "estrangeiros" para reforçar sua atuação numa sociedade que quase não os reconhece como atores sociais.

Nesta obra, apresentada por Rosita Milesi e Paula Coury, somos levados a localizar o sujeito migrante a partir de uma perspectiva em que prevalece a ótica dos direitos humanos. Afinal, segundo as autoras:

No que tange aos fluxos migratórios, forçados ou espontâneos, a adoção de uma perspectiva de Direitos Humanos é essencial para compreender as causas da

a Mestranda do Programa de Pós-Graduação em Sociologia da Universidade Federal Fluminense. Bolsista da Coordenação de Aperfeiçoamento de Pessoal de Nível Superior.

e-mail: larissamerecci@hotmail.com 
mobilidade, as trajetórias percorridas e as condições encontradas por pessoas migrantes e refugiadas nos países de trânsito e de destino. A DUDH reconhece o direito de emigrar e também de solicitar asilo. Ademais, mesmo que não haja previsão explícita do "direito de imigrar", o caráter universal e não discriminatório dos direitos e liberdades elencados pela Declaração implica em sua aplicabilidade a todo ser humano, sem distinção de qualquer natureza. Isso deve incluir, portanto, pessoas refugiadas e migrantes, independentemente de sua condição migratória (MIlEsi; Coury, 2018, p. 10).

Com isso, o Caderno de debates nos introduz aos artigos desenvolvidos por pesquisadores da área que propõem uma discussão mais ampla sobre o campo de estudos da imigração no Brasil. Apresentam também, ao final, "Os 100 pontos de Brasília” (2018, p 103), isto é, “[...] documento de experiências regionais no campo da proteção de pessoas solicitantes do reconhecimento da condição de refugiado, refugiadas, deslocadas e apátridas na região”.

Ao todo são quatro os artigos que contribuem pertinentemente para o debate da mobilidade em terras brasileiras, referindo-se ao caso de venezuelanos que se veem forçados a abandonar sua pátria na esperança de uma vida melhor no Brasil, e às leis brasileiras que respaldam o tratamento dispensado ao imigrante afinal, é importante que se estimule não apenas uma percepção mais crítica sobre como recebemos o indivíduo estrangeiro, mas também sua própria humanização enquanto sujeitos.

Seguindo este raciocínio, Rosita Milesi e Paula Coury pensam os fluxos migratórios na América Latina a partir de uma visão mais humanizada, centrada na Declaração Universal dos Direitos Humanos e na necessidade de mudança de mentalidade a respeito dos sujeitos que imigram. Da época final do Brasil Império aos dias do governo Vargas, o imigrante era visto como elemento laboral, sendo recebido unicamente com o propósito econômico de utilizá-lo como mão-de-obra barata. Entretanto, os Direitos Humanos tornaram-se importante instrumento para retificar tal ponto de vista que por tanto tempo predominou na política brasileira e que, ao que parece, é um espectro que ameaça retornar. A introdução que as autoras fazem no início deste livro é importante para situar o leitor sobre o assunto abordado pelos pesquisadores, assinalando cada ponto trabalhado por eles. Isso é bastante positivo, pois Milesi e Coury expuseram bem o foco de discussão levantado por cada autor na análise da questão sem, contudo, aprofundarem-se demasiadamente nele. 
É igualmente interessante ler, no decorrer do livro, o esforço feito para permear a questão da imigração na América Latina. Esta percepção deve ser reforçada não somente pela importância do tema atualmente - sobretudo se considerarmos os eventos políticos na Venezuela, na Bolívia, no Paraguai, e aqui no Brasil - mas porque, no meio acadêmico, há pouca atenção voltada a este enunciado. Quando pensamos a mobilidade do ator social nos dias de hoje, o foco costuma ser exclusivamente econômico, o que tende a ser perigoso porque submete o sujeito a uma interpretação laboral - e, por isso, a necessidade de uma visão humanizada que contemple outros fatores que impulsionam a migração. $\mathrm{E}$ ao direcionarmos este foco para outros países Sul-Sul, trazemos à luz sujeitos invisibilizados pelo sistema.

Da mesma maneira, abre-se um grande leque para o diálogo multidisciplinar. Gilberto M. A. Rodrigues e Luiza Fernandes e Silva produzem, de forma sucinta, uma perspectiva dentro da área de relações internacionais sobre este ponto de vista. Além disso, a orientação que embasa seu trabalho atravessa a legislação, conversando paralelamente com o direito. A sociologia, diretamente ou não, torna-se não somente um mecanismo de análise e argumentação, como também a mediação pela qual os fatos sociais são introduzidos na compreensão de estruturas sociais que concorrem para a atuação jurídica sobre a mobilidade humana.

Não obstante, essa interpretação sociológica da legislação não se limita ao Brasil, abrangendo também a forma como os países do Mercosul se comportam diante da necessidade de receber e acolher o sujeito migrante. Quanto a isso, notam-se avanços e retrocessos nas ações do Estado em suas leis. Em algumas regiões, prevalece a mudança de concepção do imigrante como "inimigo" do país em que pretende se inserir; ao contrário, as constituições de países como Uruguai e Argentina se esforçam para englobar não somente tais atores sociais como introduzi-los junto às suas culturas. Por outro lado, na Venezuela, a visão desconfiada sobre o imigrante permanece, apesar do esforço em recebê-lo bem. Contudo, a coerção com a qual a agência atua sobre o agenciado em questões irregulares aponta para o despreparo estatal para lidar com estas problemáticas. Quanto ao nosso país, as leis modificaram positivamente, preocupando-se em incorporar o indivíduo que vem de fora, ainda que as atuais circunstâncias sejam motivo de aflição. Como o governo presente lidará com os imigrantes latino-americanos, em especial os venezuelanos? Questões como essa valem para pensar a recepção legisladora, principalmente neste contexto.

No artigo seguinte, Marcia Anita Sprandel dedica seu trabalho à excelente pesquisadora Giralda Seyferth. Aqui, somos levados a um aprofundamento das leis que regem as questões pertinentes ao tema da imigração, levantando todo 
um aparato sobre a cidadania que os sujeitos migrantes se esforçam para atingir e as dificuldades que enfrentam neste processo. Ao mencionar o próprio estatuto do estrangeiro, a autora mergulha nas diferenças do tratamento direcionado ao imigrante, o que foi debatido com fervor neste livro. Novamente, ressalta-se um encaminhamento mais humanizado no esforço de mudar a antiga abordagem estritamente econômica que qualificava o forasteiro significantemente como elemento laboral para a sociedade brasileira.

Para tanto, Sprandel elabora uma genealogia dos programas presidenciais, numa comparação do governo Dilma e Temer a respeito das leis que protegiam os interesses destes estrangeiros a fim de estimular a mobilidade interna. O enfoque detalhado no direito será especialmente interessante para o leitor que deseja encontrar um elo entre esta área e a sociologia. O conteúdo do capítulo, além de se aproximar-se da sociologia, apresenta grande dedicação à questão jurídica pertinente ao tema da imigração.

Posteriormente, somos apresentados ao trabalho das autoras já previamente mencionadas nesta resenha, Rosita Milesi e Paula Coury. Nesta seção, produzida em conjunto com Julia Rovery, as pesquisadoras tratam da migração venezuelana no Brasil. Ainda que os brasileiros sejam conhecidos pela cordialidade, há algo a ser desvendado quanto aos problemas que vêm surgindo em suas relações aos vizinhos de língua espanhola. Na verdade, para Milesi, Coury e Rovery, não se pode falar cordialidade se a xenofobia vem ganhando espaço nos discursos políticos que, por sua vez, encontram respaldo na própria população que se sente ameaçada pelos imigrantes. No caso, as autoras referem-se aos constantes conflitos observados em algumas regiões do Acre e de que maneira estes são resultados não somente de diferenças culturais, mas de pensamentos e vigências preconceituosos. Em suas próprias palavras:

Todo o esforço das autoridades locais para responsabilizar a União vem sendo acompanhado pelo uso de elementos xenófobos no discurso político, os quais se fazem notar de maneira expressiva em pronunciamentos oficiais diversos e que, de maneira bastante expressiva, permeia a argumentação na qual se baseia a ACO 3121. A Ação parte da premissa de que não há dúvida que "a entrada descontrolada de venezuelanos pela fronteira Brasil/Venezuela tem causado enormes prejuízos à população deste que é o menor estado da Federação” (RoRAIMA, 2018, p. 11) (Milesi; Coury; Rovery, 2018, p. 66). 
Nesse sentido, há um esforço da parte das pesquisadoras em trazer ao público uma perspectiva mais condizente com a realidade dos refugiados em nosso país do que aquela apresentada e divulgada quase que imoralmente pela grande mídia, e que domina o pensamento social médio dos brasileiros. A fim de conscientizar o leitor do surgimento preocupante de atos xenófobos pelos brasileiros para com seus colegas latinos, as autoras apresentam dados qualitativos e quantitativos, como é o caso de registros médicos para apontar evidências de fatos como, por exemplo, os venezuelanos não foram responsáveis pelo retorno de uma doença erradicada como o sarampo. Segundo Milsey, Coury e Rovery:

Desde 2017, a Venezuela enfrenta uma epidemia de sarampo e há, de fato, indícios de que o vírus em circulação no Brasil esteja relacionado a esta situação no país vizinho (MInISTÉRIO DA SAÚdE, 2018). No entanto, o argumento discriminatório se evidencia ao se observar a solução proposta para lidar com o surto da doença, qual seja, a criação de uma barreira sanitária na fronteira. Assim, ao invés de se focar na contenção da circulação do vírus por meio de campanhas de vacinação, propõe-se impedir a circulação de pessoas, argumento repetido várias vezes por governantes locais e também por parlamentares roraimenses. Fazendo uma analogia, seria como se o combate ao surto de sarampo que ocorreu no Ceará dependesse de impedir a mobilidade da população do estado no território nacional, algo que soa absurdo (Milesi; Coury; Rovery, 2018, p. 67).

Elas discorrem, a partir do trecho citado, sobre incorrências de crimes próximos às fronteiras que ligam o Brasil à Venezuela, ressaltando, entretanto, que não há como associar diretamente a eclosão de homicídios e roubos ao fluxo migratório. Conforme pontuaram:

Argumentação de natureza semelhante é utilizada também para justificar o aumento da violência e da criminalidade em Roraima. A ACO 3121 cita dados da Polícia Civil que revelam um crescimento no número de homicídios no estado entre 2017 e 2018, fazendo uma associação automática com o fluxo migratório (Roraima, 2018, p. 10). No entanto, além de não prestar informações sobre a nacionalidade dos perpetradores, essa correlação se mostra frágil, por ignorar o fato de que o número de homicídios cometidos em Roraima vem crescendo há mais de uma década, tendo sofrido um aumento de 113,7\% entre os anos de 2005 e 2015 (CERqueira et al., 2017, p. 13), ou seja, anterior ao início do fluxo mais intensivo de venezuelanos (Milesi; Coury; Rovery, 2018, p. 68). 
O tema levanta diversos questionamentos e abre outros caminhos para estudos futuros nesse sentido. Um deles seria um mergulho nestes casos de violência: o que teria provocado uma ação deste porte e por qual motivo foi incitada a agressão? Outro igualmente valeria um diálogo com o pensamento social brasileiro, afinal, como surgiu esta xenofobia e quais foram os elementos sociais que permitiram sua construção?

No mais, as argumentações são muito bem fundamentadas, afirmadas pelo uso de metodologia. A construção do "nós" brasileiros versus "eles" venezuelanos foi, aparentemente, resultado de um pensamento pautado pelo preconceito. Este, por sua vez, surgiu da sensação de ameaça que espreitava os cidadãos de determinadas regiões do Acre. As autoras destacam, porém, que sempre houve, em certa medida, uma migração de venezuelanos para o Brasil através do Acre. Contudo, elas ressaltam também que, nos programas eleitorais, a preocupação com a imigração por si só nunca foi tão central quanto recentemente. E se agora há um receio quanto à mobilidade dos sujeitos vizinhos, ela é resultado de um preconceito infundamentado.

Segundo Milesi, Coury e Roveri (2018, p. 72), deve ser levado em conta que “[...] apesar de terem a pretensão de parecer naturais, atemporais e inquestionáveis, as fronteiras são criações humanas, resultado de processos históricos e interesses muito específicos”. Não somente isso, como também, voltando a própria questão da separação do ser brasileiro e o ser venezuelano, as autoras pontuam que:

Genova (2016), assim como Mezzadra e Neilson (2013), destacam em suas obras que as fronteiras são celebradas como se seu real propósito fosse simplesmente o de exclusão - funcionando como uma barreira que protege o que está dentro, isolando o que está fora. Essa visão apresenta consonância com as premissas expressas pelo Governo de Roraima na Ação. Nela, busca-se separar o "nós", brasileiros, e o "eles", venezuelanos, supostamente para nossa proteção. Na realidade, no entanto, as fronteiras operam como zonas amórficas que podem ser permeadas e transgredidas, apresentando-se como pontos de encontro, intercâmbio e seleção (Milesi; Coury; RoverY, 2018, p. 71).

Por isso a necessidade de estimular a inclusão de venezuelanos na sociedade na qual esforçam-se em fazer parte, ou, em outras palavras: os conflitos que existem não devem ser incentivados, mas estudados para serem prevenidos. É curioso como isso reflete a posição do estrangeiro tal qual Georg Simmel o estudou em seu artigo intitulado "O Estrangeiro" (2005). Em diálogo com o sociólogo alemão, as 
mencionadas autoras pontuam a necessidade de interações entre o próprio sujeito e a comunidade que, a princípio, lhe é estranha. Nesse sentido, seu artigo atrai particularmente o estudioso da área de imigração pelas possibilidades de diálogo com a sociologia clássica. Reforça, principalmente, a importância de autores como Simmel e Weber para seu entendimento ainda que não tenham sido utilizados para pensar os conflitos entre os venezuelanos e os brasileiros.

Contudo, é possível que Simmel seja melhor aplicado ao trabalho de Filipe Rezende Silva em conjunto com Duval Fernandes, que trata dos imigrantes haitianos. Embora ambos sejam geógrafos, reforçando o discurso multidisciplinar com a sociologia da imigração, como apontado anteriormente, a forma com a qual se apropriaram da disciplina para este estudo fica bastante evidente, a começar, pelo título, "Desafios enfrentados pelos imigrantes no processo de integração à sociedade brasileira”, e que nos remete ao próprio conceito de estrangeiro elaborado pelo sociólogo clássico:

O estrangeiro (...) é também um elemento do grupo, não mais diferente que os outros e, ao mesmo tempo, distinto do que consideramos como o "inimigo interno". É um elemento do qual a posição imanente e de membro compreendem, ao mesmo tempo, em exterior e um contrário (Simmel, 2005, p. 5).

Em contrapartida, se o imigrante é visto pela coletividade como "inimigo interno", as dificuldades pelas quais ele passará podem colocá-lo à marginalidade desta sociedade, dificultando sua inserção nela, onde será sempre visto com desconfiança. Ainda que haja um esforço para que as leis brasileiras não disponham dessa concepção de imigrante como inimigo do Estado, conflitos como os vistos entre venezuelanos e brasileiros ainda resultam deste tratamento. Cabe destacar aqui a preocupação de Silva e Fernandes com a inserção do imigrante na sociedade:

Em relação ao processo de inserção dos imigrantes na sociedade brasileira, alguns obstáculos foram verificados, tais como o acolhimento, o domínio da língua e a questão da discriminação racial e xenofobia. Esses fatos, em conjunto ou isolados, acabam se tornando um empecilho para a inserção dos imigrantes na sociedade brasileira, podendo até ocasionar sua exclusão do convívio social (Silva; Fernandes, 2018, p. 84).

No decorrer deste artigo, as dificuldades abordadas apontam para além do discurso xenófobo mascarado pela aparente amabilidade dos brasileiros para com 
os estrangeiros recebidos. Contudo, questiona-se o próprio uso do termo "estrangeiro", afinal, ele é direcionado para um tipo de forasteiro - o branco, colonizador - enquanto que o termo "imigrante" é atribuído ao negro, pobre. É enriquecedor para o leitor os relatos que os autores se esforçam em trazer ao público, pois eles ilustram uma realidade que é, para muitos, racista e excludente.

No estudo sobre os haitianos que chegam ao Brasil, por exemplo, compreendemos que as diferenças culturais colaboram ainda mais para sua marginalização na sociedade. Apesar disso, os autores buscam e confrontam tais obstáculos com propostas realistas do que poderia ser feito para a inserção destes sujeitos à sociedade brasileira. Aqui, a metodologia de pesquisa enriquece o trabalho dos pesquisadores, tendo em vista a predominância tanto do método quantitativo, pelo bom manejo de dados através do uso de gráficos, quanto do qualitativo, pela coleta dos relatos através de entrevistas. Todo este material empírico dialoga muito, e poderia ser apropriado, pela sociologia clássica de Simmel, embora nada também nos impeça de lembrarmos da fenomenologia de Alfred Schutz, a construção social de Peter Berger e outros autores da sociologia contemporânea cujos conceitos sociológicos também são usados por aqueles que atuam na área da imigração.

Para concluir, o documento oficial que foi mencionado na introdução desta resenha fecha esta edição do Caderno de debates. Chamado de "Os 100 pontos de Brasília - Contribuições da América Latina e do Caribe para o Pacto Global sobre refugiados", trata-se de documento longo e que nos surpreendeu por ter sido incluído na obra. Sua inclusão reforça a seriedade do debate em torno não apenas dos refugiados e outros imigrantes, como do assunto da imigração em si, atribuída por tantos leigos a um problema da contemporaneidade. São, como o título indica, 100 pontos voltados para uma série de questões envolvendo imigrantes e refugiados, sobre acolhimento em países do Sul como quanto à preocupação em inseri-los em suas sociedades. Tais pontos enfatizam a humanidade destes indivíduos, que carregam consigo memórias e processos de socialização próprios, e que muitas vezes não escolheram abandonar suas casas para tentar algo novo em um lugar que lhes é estranho. Embora os países que recebem tais sujeitos possuem o infeliz costume de trata-los como números para suas economias, esquecendo-se, deste modo, de que não foi apenas para o mercado de trabalho que vieram, felizmente vem crescendo um esforço para cambiar os tipos de tratamento a eles como cada artigo prontamente pontuou.

A leitura deste livro, embora possa ser feito de maneira célere, é recomendável para os que desejam aprofundar o conhecimento sobre o tema de maneira multidisciplinar, dialogando com as áreas do direito e da geografia, e também para aqueles 
que possuem interesse no assunto. É pertinente para a sociologia da imigração por propor novas abordagens dentro deste campo, salientando discussões que não devem ser relegadas ao esquecimento ou negligência. Para o pesquisador desta área, e principalmente para os que se propõem pesquisar estas questões em específico, a bibliografia utilizada por cada autor é rica e muito colaborativa. Sendo assim, recomendamos esta obra.

\section{REFERÊNCIAS BIBLIOGRÁFICAS}

Milesi, Rosita; Coury, Paula (Org.). Caderno de Debates Refúgio, Migrações e Cidadania. Brasília: Instituto Migrações e Direitos Humanos, v. 13, n. 13, 2018. 124 p.

Milesi, Rosita; Coury, Paula; Rovery, Julia. "Migração Venezuelana ao Brasil: discurso político e xenofobia no contexto atual”. In: Milesi, Rosita; Coury, Paula (Org.). Caderno de Debates Refúgio, Migrações e Cidadania. Brasília: Instituto Migrações e Direitos Humanos, v. 13, n. 13, 2018, p 60-81.

Silva, Filipe Rezende; Fernandes, Duval. "Desafios enfrentados pelos imigrantes no processo de integração à sociedade brasileira”. In: Milesi, Rosita; Coury, Paula (Org.). Caderno de Debates Refúgio, Migrações e Cidadania. Brasília: Instituto Migrações e Direitos Humanos, v. 13, n. 13, 2018, p. 83-102.

Simmel, Georg. O Estrangeiro. Revista Brasileira Sociologia da Emoção, v. 4, n. 12, 2005.

Recebido: 11/10/2019 | Aprovado: 30/03/2020 